\title{
Association between echocardiographic structural parameters and body weight in Wistar rats
}

\author{
Silvio A. Oliveira-Junior ${ }^{1, *}$, Paula F. Martinez ${ }^{1, *}$, William Y.C. Fan ${ }^{2, *}$, Bruno T. \\ Nakatani ${ }^{2,}{ }^{*}$, Luana U. Pagan ${ }^{2, *}$, Carlos R. Padovani ${ }^{3, *}$, Antonio C. Cicogna ${ }^{2, *}$, Marina P. \\ Okoshi $^{2, *}$, Katashi Okoshi ${ }^{2, *}$ \\ ${ }^{1}$ School of Physical Therapy, Federal University of Mato Grosso do Sul, Campo Grande, MS, Brazil \\ ${ }^{2}$ Botucatu Medical School, Sao Paulo State University, UNESP, Botucatu, SP, Brazil \\ ${ }^{3}$ Botucatu Biosciences Institute, Sao Paulo State University, UNESP, Botucatu, SP, Brazil \\ *These authors take responsibility for all aspects of the reliability and freedom from bias of the data presented and their \\ discussed interpretation
}

Correspondence to: Katashi Okoshi, email: katashi@fmb.unesp.br

Keywords: development, physiological cardiac remodeling, rat, echocardiogram, cardiac structures

Received: November 16, $2016 \quad$ Accepted: January 26, $2017 \quad$ Published: February 13, 2017

Copyright: Oliveira-Junior et al. This is an open-access article distributed under the terms of the Creative Commons Attribution License (CC-BY), which permits unrestricted use, distribution, and reproduction in any medium, provided the original author and source are credited.

\section{ABSTRACT}

Background: The association between echocardiographic structural parameters and body weight (BW) during rat development has been poorly addressed. We evaluated echocardiographic variables: left ventricular (LV) end-diastolic (LVDD) and end-systolic (LVSD) diameters, LV diastolic posterior wall thickness (PWT), left atrial diameter (LA), and aortic diameter (AO) in function of BW during development.

Results/Materials and Methods: Male Wistar rats ( $n=328, \mathrm{BW}$ : 302-702 g) were retrospectively used to construct regression models and $95 \%$ confidence intervals relating to cardiac structural parameters and BW. Adjusted indexes were significant to all relationships; the regression model for predicting LVDD $(R 2=0.678$; $p<0.001)$ and $A O(R 2=0.567 ; p<0.001)$ had the highest prediction coefficients and LA function the lowest prediction coefficient $(R 2=0.274 ; p<0.01)$. These relationships underwent validation by performing echocardiograms on additional rats ( $n=43, \mathrm{BW}: 300-600 \mathrm{~g})$ and testing whether results were within confidence intervals of our regressions. Prediction models for AO and LA correctly allocated $38(88.4 \%)$ and 39 rats $(90.7 \%)$, respectively, within the $95 \%$ confidence intervals. Regression models for LVDD, LVSD, and PWT included 27 (62.7\%), 30 (69.8\%), and $19(44.2 \%)$ animals, respectively, within the $95 \%$ confidence intervals.

Conclusions: Increase in cardiac structures is associated with BW gain during rat growth. LA and AO can be correctly predicted using regression models; prediction of PWT and LV diameters is not accurate.

\section{INTRODUCTION}

Animal models are highly relevant in evaluating cardiac remodeling under different situations of injury and in developing treatment strategies for alleviating heart disease in humans [1-3]. Although large mammalian species are considered more relevant for simulating human disease, rats are commonly used for economic reasons.

Transthoracic echocardiography is a recognized safe, reliable, and repeatable diagnostic method which has been extensively used to evaluate structural and functional cardiac parameters in rats [4]. Being noninvasive in nature, it can be used to perform longitudinal studies on cardiac remodeling pathophysiology and treatment. Baseline echocardiographic values for cardiac anatomy and function have been documented for normal adult and aged rats [5-7].

Cardiac structural parameters such as left ventricular (LV) diastolic diameter, LV mass, and left atrial diameter are often normalized to body weight to compensate for small changes in body mass $[8,9]$. However, this does not take into account that the relationship between cardiac structures and body size is nonlinear $[10,11]$. This normalization may therefore under or overcorrect for 
the impact of body size when evaluating rats with severe body weight change conditions such as undernutrition, obesity, or cardiac and cancer cachexia. To date, the relationship between cardiac structures and body weight during rat development has not been investigated. This study evaluates echocardiographic variables LV enddiastolic and end-systolic diameters, LV diastolic posterior wall thickness, left atrial diameter, and aortic diameter in function of body weight during normal development in Wistar rats. The high number of ongoing rat cardiac remodeling studies in our laboratory allowed us to perform this work using a large number of animals [12-14].

\section{RESULTS}

\section{Retrospective study}

Rat body weight ( $n=328$ ) ranged from 302 to $702 \mathrm{~g}$. Following descriptive analysis, 36 body mass categories were obtained (example: 300-309 g, 310-319 g, etc). Different regression models were then built to analyze the behavior of LVDD, LVSD, PWT, LA, and AO in function of the body weight (Table 1). Confidence intervals for each regression model are shown in Figure 1. Adjusted indexes were statistically significant for all relationships. The regression model for predicting LVDD and aortic diameter presented the highest prediction coefficients, and the model for predicting left atrial diameter the lowest prediction coefficient (Table 1).

\section{Prospective study}

To validate the relationships between cardiac structural parameters and body weight obtained in the retrospective study, we prospectively performed echocardiograms on additional rats $(n=43)$ with body weights ranging from 300 to $600 \mathrm{~g}$ and tested whether results were inside the confidence intervals of our regressions. Figure 2 shows parameter percentage values included in the $95 \%$ confidence intervals. Prediction models for aortic diameter and left atrial diameter correctly allocated 38 (88.4\%) and 39 animals (90.7\%), respectively, within the $95 \%$ confidence intervals. Regression models for LVDD and LVSD correctly included 27 (62.7\%) and $30(69.8 \%)$ rats, respectively, and regression function for PWT only correctly allocated 19 rats $(44.2 \%)$.

\section{DISCUSSION}

Transthoracic echocardiography has been extensively used to evaluate in vivo cardiac structures and ventricular function in rodents. This noninvasive technique allows longitudinal studies of cardiac remodeling induced by different types of aggression and the effects of therapeutic interventions [15-17]. Transthoracic echocardiography has also been used to examine cardiac remodeling caused by systemic diseases which are accompanied by losses or gains in body weight, such as undernutrition, cachexia, obesity, and aging [18-21]. In
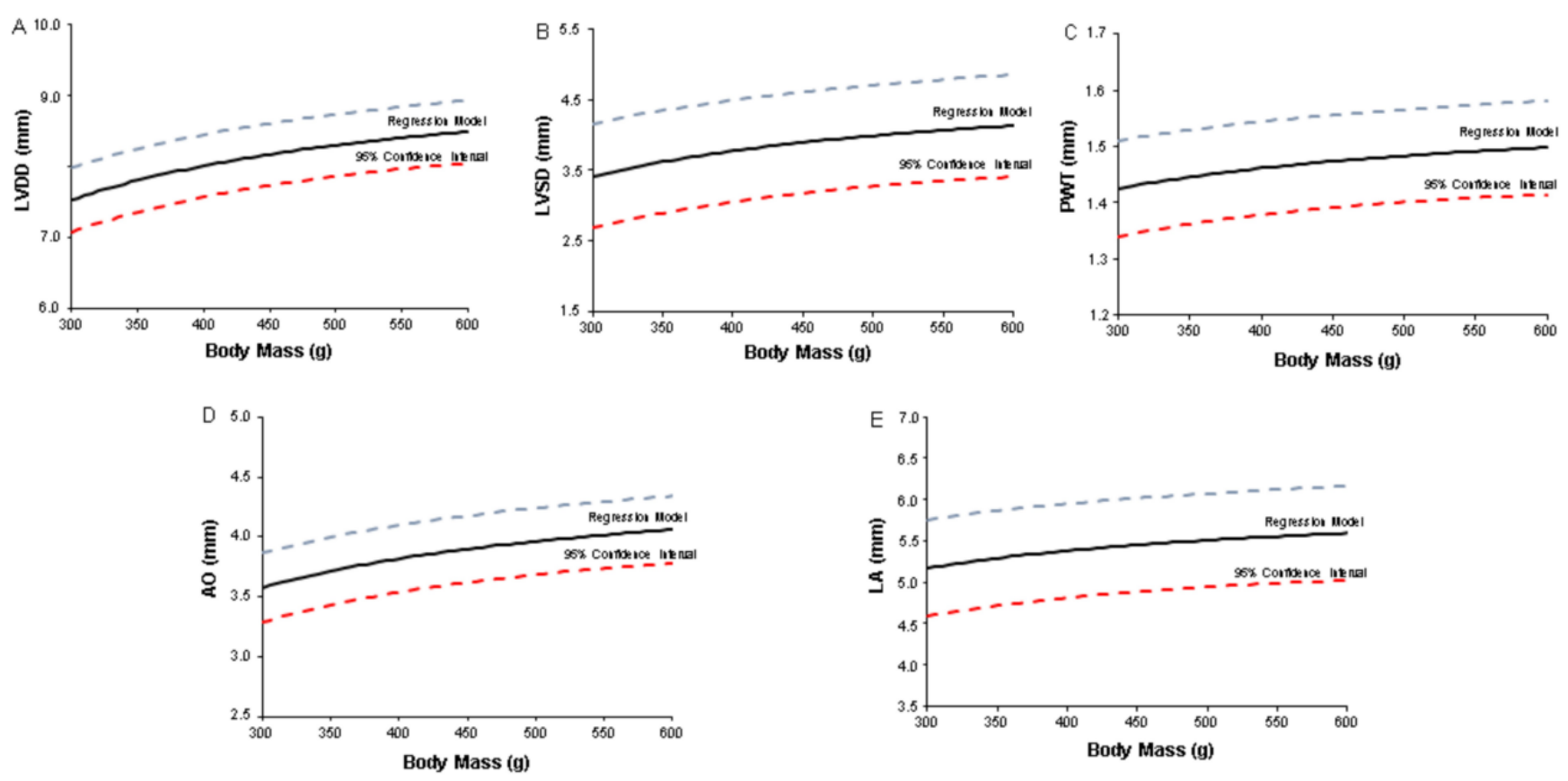

Figure 1: Regression models and 95\% confidence intervals for (A) left ventricular (LV) end-diastolic diameter (LVDD), (B) LV end-systolic diameter (LVSD), (C) LV diastolic posterior wall thickness (PWT), (D) aortic diameter (AO), and (E) left atrial diameter (LA) in accordance with Wistar rat body weight. Straight line: regression model; dashed lines: superior and inferior $95 \%$ confidence intervals. 
Table 1: Non-linear regression models for cardiac structures in function of body weight

\begin{tabular}{lcccc}
\hline \multicolumn{1}{c}{ Regression } & $\begin{array}{c}\text { Coefficient of } \\
\text { Determination }\left(\mathbf{R}^{2}\right)\end{array}$ & $\boldsymbol{P}$-value & Variation Model & MSE \\
\hline LVDD $=9.453-577.331 / \mathrm{BW}$ & 0.678 & $p<0.001$ & (LVDD) $^{\prime}=577.331 / \mathrm{BW}^{2}$ & 0.0451 \\
$\mathrm{LVSD}=4.845-428.215 / \mathrm{BW}$ & 0.303 & $p<0.001$ & $(\mathrm{LVSD})^{\prime}=428.215 / \mathrm{BW}^{2}$ & 0.1200 \\
$\mathrm{PWT}=1.571-43.730 / \mathrm{BW}$ & 0.256 & $p<0.005$ & $(\mathrm{PWT})^{\prime}=43.730 / \mathrm{BW}^{2}$ & 0.0016 \\
$\mathrm{AO}=4.542-289.199 / \mathrm{BW}$ & 0.567 & $p<0.001$ & $(\mathrm{AO})^{\prime}=289.199 / \mathrm{BW}^{2}$ & 0.0182 \\
$\mathrm{LA}=6.012-252.568 / \mathrm{BW}$ & 0.274 & $p<0.01$ & $(\mathrm{LA})^{\prime}=252.568 / \mathrm{BW}^{2}$ & 0.0749 \\
\hline
\end{tabular}

LVDD: left ventricular (LV) end-diastolic diameter; LVSD: LV end-systolic diameter; PWT: LV posterior wall diastolic thickness; AO: aortic diameter; LA: left atrial diameter; BW: body weight; MSE: mean square error.

this context, cardiac structures are commonly related to body size to establish reference standards for normality and permit intergroup comparisons [22-24].

In this study, we aimed to construct $95 \%$ confidence intervals for normal cardiac structure values in rats with body weights ranging from 302 to $702 \mathrm{~g}$. We selected echocardiographic parameters of cardiac structures that are classical descriptors in several cardiovascular conditions [25-27]. Despite linear relationships between cardiac structures and body mass in the early growth phase, these relationships become complex and nonlinear in later development periods up to adulthood. Therefore, as expected, all analyzed variables presented nonlinear relationships with body weight showing that during normal growth, cardiac structures do not increase linearly with body mass gain. To the best of our knowledge, this is the first study to evaluate associations between cardiac structures and body development up to adult age using a large sample of rats.

Although the regression model coefficient of determination for LVDD was strongly associated with body mass, prospective evaluation found that only

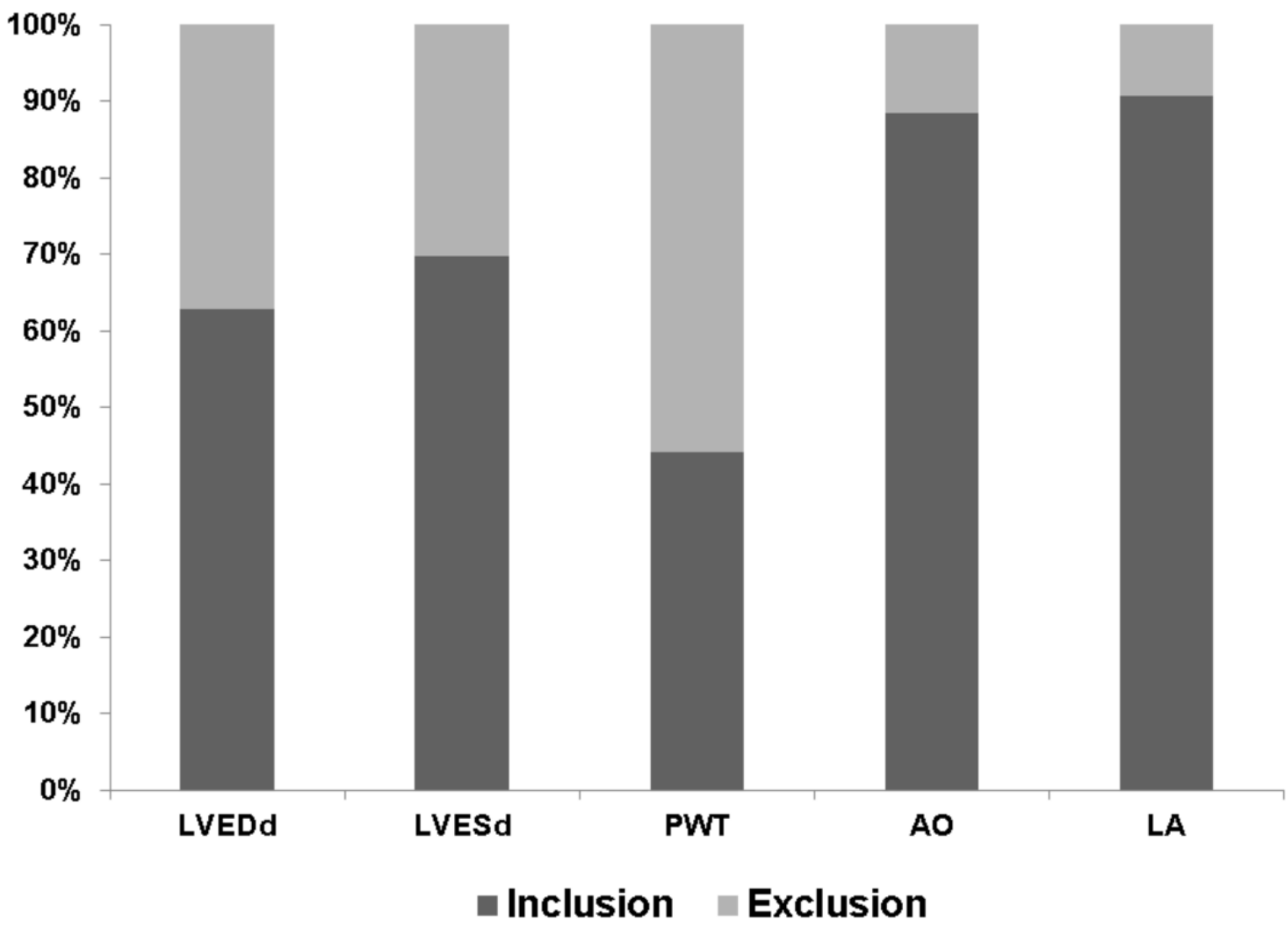

Figure 2: Percentages of echocardiographic parameters falling within regression model $95 \%$ confidence intervals for prospectively evaluated Wistar rats with body weights ranging from 300 to $600 \mathbf{g}(\boldsymbol{n}=\mathbf{4 3})$. LVDD: left ventricular (LV) end-diastolic diameter, LVSD: LV end-systolic diameter, PWT: LV diastolic posterior wall thickness, AO: aortic diameter, LA: left atrial diameter. 
$62.8 \%$ of LVDD values were within the $95 \%$ confidence intervals. Similarly, LVSD and PWT regression models demonstrated a poor potential for predicting values in normal rats $(69.8 \%$ and $44.2 \%$, respectively). However, despite presenting a low coefficient of determination in the retrospective study, the left atrial diameter regression model produced the best prospective prediction score $(90.7 \%)$. The aortic diameter regression model was also a good predictor $(88.4 \%)$ for normal rats. Therefore, normal values for left atrium and aorta diameters can be obtained by using our regression models when evaluating Wistar rats with different body weights. A similar approach was employed by Ahmet et al. [28] using sophisticated allometric scaling procedures to evaluate the effects of calorie restriction on cardioprotection in Fisher rats. As our LV diameter regression models included less than 70\% of rats in the normal range, we should be careful when using mathematical models to estimate values for normal LV diameters.

A limitation of this study is that we evaluated only male Wistar rats. Therefore, additional studies are required to ascertain whether our results are valid for female Wistar rats and other rat strains.

In conclusion, cardiac structure increase is associated with body weight gain during Wistar rat growth. Left atrial and aortic diameters can be correctly predicted using regression models; however, left ventricular wall thickness and diameters prediction is not accurate.

\section{MATERIALS AND METHODS}

\section{Animals}

Two sets of animals were studied. The first set of rats was used to perform retrospective analysis and the second to prospectively validate results obtained in the initial study. All experiments and procedures were approved by the Ethics Committee of Botucatu Medical School, Sao Paulo State University, UNESP, SP, Brazil, and were in accordance with the "Guide for the Care and Use of Laboratory Animals" published by the US National Institutes of Health.

The retrospective study used data from male adult Wistar rats $(n=328)$ previously evaluated in our laboratory. All animals had been housed in a temperature controlled room at $23^{\circ} \mathrm{C}$ to $24^{\circ} \mathrm{C}$ on a 12 -h light/dark cycle with free access to water and chow. Rats were euthanized at different ages and body weights according to the respective experimental protocols. Rats had been weighed and subjected to transthoracic echocardiography within one or two days of euthanasia.

For the prospective analysis, male Wistar rats (200-250 g, 50-60 days old; $n=43$ ) were purchased from the Central Animal House at Botucatu Medical School, UNESP, and kept as previously described. These rats were assigned into seven groups ( $n=6-7$ per group) for body weight evaluation and echocardiogram after achieving the following body weights: $300,350,400,450,500,550$, and $600 \mathrm{~g}$.

\section{Echocardiographic study}

Echocardiographic evaluation was performed using a commercially available echocardiograph (General Electric Medical Systems, Vivid S6, Tirat Carmel, Israel) equipped with a 5-11.5 MHz multifrequency probe, as previously described [29-31]. Rats were anesthetized by intramuscular injection of ketamine $(50 \mathrm{mg} / \mathrm{kg})$ and xylazine $(0.5 \mathrm{mg} / \mathrm{kg})$. Two-dimensional guided M-mode images were obtained from parasternal short-axis views of the LV just below the tip of the mitral-valve leaflets, and at the level of the aortic valve and left atrium. M-mode images were printed on a thermal printer (Sony UP$890 \mathrm{MD}$ ) at a sweep speed of $200 \mathrm{~mm} / \mathrm{s}$. All LV structures were manually measured by the same observer (KO) using the leading-edge method of the American Society of Echocardiography [32]. Mean values were obtained from at least five cardiac cycles on M-mode tracings. The following structural variables were measured: left atrial diameter, aortic diameter, LV end-diastolic and endsystolic diameters (LVDD and LVSD, respectively), and LV diastolic posterior wall thickness (PWT). Intraobserver reproducibility of echocardiographic variables has been previously published [4].

\section{Statistical analysis}

All analyzes were carried out using the SPSS statistical software package (Release 6.0 for Windows; SPSS, Chicago, IL). In the retrospective study, relationships between body mass and echocardiographic parameters were determined from dispersion diagrams and regression models were constructed [33]. Higher coefficient of determination scores $(R 2)$ were considered for selecting the better prediction model. Using functions obtained by regression analysis, $95 \%$ confidence intervals were built and used to prospectively investigate the accuracy of predictive echocardiographic parameters values in healthy rats. Statistical significance was accepted at $P<0.05$.

\section{Abbreviations}

AO: aortic diameter, BW: body weight, LA: left atrial diameter, LV: left ventricular, LVDD: left ventricular end-diastolic diameter, LVSD: left ventricular end-systolic diameter, MSE: mean square error, PWT: left ventricular diastolic posterior wall thickness.

\section{ACKNOWLEDGMENTS}

The authors are grateful to Jose Carlos Georgette for their technical assistance and Colin Edward Knaggs for English editing. 


\section{CONFLICTS OF INTEREST}

The authors report no relationship that could be construed as a conflict of interest.

\section{GRANT SUPPORT}

Financial support was provided by $\mathrm{CNPq}$ (308674/2015-4, 306770/2015-6), FAPESP (2014/219723, 2015/17539-5), CAPES, and PROPe, UNESP.

\section{Authors' contributions}

SAO-J, MPO, and KO contributed to conception and design of study, acquisition of data, analysis and interpretation of data, and manuscript writing; PFM, WYCF, BTN, and ACC contributed to data collection; SAO-J and CRP contributed to statistical analysis; All authors have given final approval of the version to be published.

\section{REFERENCES}

1. Okoshi MP, Cezar MD, Iyomasa RM, Silva MB, Costa LC, Martinez PF, Campos DH, Damatto RL, Minicucci MF, Cicogna AC, Okoshi K. Effects of early aldosterone antagonism on cardiac remodeling in rats with aortic stenosisinduced pressure overload. Int J Cardiol. 2016; 222:569-575.

2. Guizoni DM, Oliveira-Junior SA, Noor SL, Pagan LU, Martinez PF, Lima AR, Gomes MJ, Damatto RL, Cezar MD, Bonomo C, Zornoff LA, Okoshi K, Okoshi MP. Effects of late exercise on cardiac remodeling and myocardial calcium handling proteins in rats with moderate and large size myocardial infarction. Int J Cardiol. 2016; 221:406-412.

3. Chen XY, Lv RJ, Zhang W, Yan YG, Li P, Dong WQ, Liu X, Liang ES, Tian HL, Lu QH, Zhang MX. Inhibition of myocyte-specific enhancer factor $2 \mathrm{~A}$ improved diabetic cardiac fibrosis partially by regulating endothelial-tomesenchymal transition. Oncotarget. 2016; 7:31053-31066. doi: 10.18632/oncotarget.8842.

4. Martinez PF, Okoshi K, Zornoff LA, Oliveira SA Jr, Campos DH, Lima AR, Damatto RL, Cezar MD, Bonomo C, Guizoni DM, Padovani CR, Cicogna AC, Okoshi MP. Echocardiographic detection of congestive heart failure in postinfarction rats. J Appl Physiol. 2011; 111:543-551.

5. Watson LE, Sheth M, Denyer RF, Dostal DE. Baseline echocardiographic values for adult male rats. J Am Soc Echocardiogr. 2004; 17:161-167.

6. Boluyt MO, Converso K, Hwang HS, Mikkor A, Russell MW. Echocardiographic assessment of ageassociated changes in systolic and diastolic function of the female F344 rat heart. J Appl Physiol. 2004; 96:822-828.

7. Hacker TA, McKiernan SH, Douglas PS, Wanagat J, Aiken JM. Age-related changes in cardiac structure and function in Fischer 344 x Brown Norway hybrid rats. Am J Physiol Heart Circ Physiol. 2006; 290:H304-H311.
8. Rosa CM, Xavier NP, Henrique Campos D, Fernandes AA, Cezar MD, Martinez PF, Cicogna AC, Gimenes C, Gimenes R, Okoshi MP, Okoshi K. Diabetes mellitus activated fetal gene program and intensifies cardiac remodeling and oxidative stress in aged spontaneously hypertensive rats. Cardiovasc Diabetol. 2013; 12:152.

9. Damatto RL, Martinez PF, Lima AR, Cezar MD, Campos DH, Oliveira Junior SA, Guizoni DM, Bonomo C, Nakatani BT, Dal Pai Silva M, Carvalho RF, Okoshi K, Okoshi MP. Heart failure-induced skeletal myopathy in spontaneously hypertensive rats. Int J Cardiol. 2013; 167:698-703.

10. Nevill AM, Ramsbottom R, Williams C. Scaling physiological measurements for individuals of different body size. Eur J Appl Physiol Occup Physiol. 1992; 65:110-117.

11. Chantler PD, Clements RE, Sharp L, George KP, Tan LB, Goldspink DF. The influence of body size on measurements of overall cardiac function. Am J Physiol Heart Circ Physiol. 2005; 289:H2059-H2065.

12. Gimenes C, Gimenes R, Rosa CM, Xavier NP, Campos DH, Fernandes AA, Cezar MD, Guirado GN, Cicogna AC, Takamoto AH, Okoshi MP, Okoshi K. Low intensity physical exercise attenuates cardiac remodeling and myocardial oxidative stress and dysfunction in diabetic rats. J Diabetes Res. 2015:ID 457848.

13. Guimaraes JF, Muzio BP, Rosa CM, Nascimento AF, Sugizaki MM, Fernandes AA, Cicogna AC, Padovani CR, Okoshi MP, Okoshi K. Rutin administration attenuates myocardial dysfunction in diabetic rats. Cardiovasc Diabetol. 2015; 14:90.

14. Martins F, Campos DH, Pagan LU, Martinez PF, Okoshi K, Okoshi MP, Padovani CR, Souza AS, Cicogna AC, OliveiraJunior SA. High-fat diet promotes cardiac remodeling in an experimental model of obesity. Arq Bras Cardiol. 2015; 105:479-486.

15. Oliveira-Junior SA, Martinez PF, Guizoni DM, Campos DH, Fernandes T, Oliveira EM, Okoshi MP, Okoshi K, Padovani CR, Cicogna AC. AT1 receptor blockade attenuates insulin resistance and myocardial remodeling in rats with diet-induced obesity. PLoS One. 2014; 9:e86447.

16. Oliveira Junior SA, Dal Pai-Silva M, Martinez PF, LimaLeopoldo AP, Campos DH, Leopoldo AS, Okoshi MP, Okoshi K, Padovani CR, Cicogna AC. Diet-induced obesity causes metabolic, endocrine and cardiac alterations in spontaneously hypertensive rats. Med Sci Monit. 2010; 16:BR367-BR373.

17. Hong MN, Li XD, Chen DR, Ruan CC, Xu JZ, Chen J, Wu YJ, Ma Y, Zhu DL, Gao PJ. Renal denervation attenuates aldosterone expression and associated cardiovascular pathophysiology in angiotensin II-induced hypertension. Oncotarget. 2016; 7:67828-67840. doi: 10.18632/oncotarget.12182.

18. Okoshi K, Matsubara LS, Okoshi MP, Cicogna AC, Fioretto JR, Padovani CR, Aragon FF, Matsubara BB. Food restriction-induced myocardial dysfunction demonstrated by the combination of in vivo and in vitro studies. Nutr Res. $2002 ; 22: 1353-1364$. 
19. Dong WQ, Chao M, Lu QH, Chai WL, Zhang W, Chen XY, Liang ES, Wang LB, Tian HL, Chen YG, Zhang MX. Prohibitin overexpression improves myocardial function in diabetic cardiomyopathy. Oncotarget. 2016; 7:66-80. doi: 10.18632/oncotarget.6384.

20. Oliveira Junior SA, Padovani CR, Rodrigues SA, Silva NR, Martinez PF, Campos DH, Okoshi MP, Okoshi K, DalPai M, Cicogna AC. Extensive impact of saturated fatty acids on metabolic and cardiovascular profile in rats with diet-induced obesity: a canonical analysis. Cardiovasc Diabetol. 2013; 12:65.

21. Pagan LU, Damatto RL, Cezar MD, Lima AR, Bonomo C, Campos DH, Gomes MJ, Martinez PF, Oliveira SA Jr, Gimenes R, Rosa CM, Guizoni DM, Moukbel YC, et al. Long-term low intensity physical exercise attenuates heart failure development in aging spontaneously hypertensive rats. Cell Physiol Biochem. 2015; 36:61-74.

22. Lima AR, Martinez PF, Damatto RL, Cezar MD, Guizoni DM, Bonomo C, Oliveira SA Jr, Dal-Pai Silva M, Zornoff LA, Okoshi K, Okoshi MP. Heart failure-induced diaphragm myopathy. Cell Physiol Biochem. 2014; 34:333-345.

23. Martinez PF, Bonomo C, Guizoni DM, Junior SA, Damatto RL, Cezar MD, Lima AR, Pagan LU, Seiva FR, Fernandes DC, Laurindo FR, Novelli EL, Matsubara LS, et al. Influence of n-acetylcysteine on oxidative stress in slow-twitch soleus muscle of heart failure rats. Cell Physiol Biochem. 2015; 35:148-159.

24. Cezar MD, Damatto RL, Martinez PF, Lima AR, Campos DH, Rosa CM, Guizoni DM, Bonomo C, Cicogna AC, Gimenes R, Pagan LU, Okoshi MP, Okoshi K. Aldosterone blockade reduces mortality without changing cardiac remodeling in spontaneously hypertensive rats. Cell Physiol Biochem. 2013; 32:1275-1287.

25. Michel FS, Magubane M, Mokotedi L, Norton GR, Woodiwiss AJ. Sex-specific effects of adrenergic-induced left ventricular remodeling in spontaneously hypertensive rats. J Card Fail. 2016; 23:161-168.

26. Felix AC, Dutra SG, Tezini GC, Simões MV, de Souza HC. Aerobic physical training increases contractile response and reduces cardiac fibrosis in rats subjected to early ovarian hormone deprivation. J Appl Physiol. 2015; 118:1276-1285.

27. Cezar MD, Damatto RL, Pagan LU, Lima AR, Martinez PF, Bonomo C, Rosa CM, Campos DH, Cicogna AC, Gomes MJ, Oliveira SA Jr, Blotta DA, Okoshi MP, et al. Early spironolactone treatment attenuates heart failure development by improving myocardial function and reducing fibrosis in spontaneously hypertensive rats. Cell Physiol Biochem. 2015; 36:1453-1466.

28. Ahmet I, Wan R, Mattson MP, Lakatta EG, Talan M. Cardioprotection by intermittent fasting in rats. Circulation. 2005; 112:3115-3121.

29. Okoshi K, Fioretto JR, Okoshi MP, Cicogna AC, Aragon FF, Matsubara LS, Matsubara BB. Food restriction induces in vivo ventricular dysfunction in spontaneously hypertensive rats without impairment of in vitro myocardial contractility. Braz J Med Biol Res. 2004; 37:607-613.

30. Martinez PF, Okoshi K, Zornoff LA, Carvalho RF, Oliveira Junior SA, Lima AR, Campos DH, Damatto RL, Padovani CR, Nogueira CR, Dal Pai-Silva M, Okoshi MP. Chronic heart failure-induced skeletal muscle atrophy, necrosis, and myogenic regulatory factors changes. Med Sci Monit. 2010; 16:374-383.

31. Damatto RL, Lima AR, Martinez PF, Cezar MD, Okoshi K, Okoshi MP. Myocardial myostatin in spontaneously hypertensive rats with heart failure. Int J Cardiol. 2016; 215:384-387.

32. Lang RM, Badano LP, Mor-Avi V, Afilalo J, Armstrong A, Ernande L, Flachskampf FA, Foster E, Goldstein SA, Kuznetsova T, Lancellotti P, Muraru D, Picard MH, et al. Recommendations for cardiac chamber quantification by echocardiography in adults: an update from The American Society of Echocardiography and The European Association of Cardiovascular Imaging. Eur Heart J Cardiovasc Imaging. 2015; 16:233-270.

33. Draper NR, Smith H. Applied regression analysis. New York: John Wiley; 1998. 